\title{
LOUISE HOWARD
}

\section{Women in academic psychiatry}

Despite recent gains in admissions to medical school and most specialities, a glance at the list of academic staff of most university departments of psychiatry makes it clear that women are under-represented at senior academic ranks. There is evidence from the USA that although women are now more likely to enter academic medicine than their male counterparts, women are less likely than men to advance to the senior ranks of academic medicine (Nonnemaker, 2000). Killaspy et al (2003, this issue) have examined academic psychiatry in the UK and claim that women are less likely to pursue an academic career in psychiatry and within academia, they are less likely to reach professorial positions - the glass ceiling again.

Unfortunately, it is impossible to be entirely systematic in a study of this kind in the UK because there is no centrally collected source of the necessary data. Many researchers start as honorary specialist registrars, funded by project grants, and would not have been included in this survey. Some of the data collected does not support Killaspy et al's main argument. Women appeared just as likely to obtain Wellcome Trust and Medical Research Council training fellowships - in the future, these women could do just as well as men. However, they argue that although there are equal numbers of men and women at specialist registrar level and the gender disparity at consultant level may therefore reduce in the future, this seems less likely in academic psychiatry.

Does it matter whether women are underrepresented in academic psychiatry? The profession needs the best people to contribute to our understanding of psychiatric disorders, develop innovative treatments and improve our mental health services. If women are excluded, institutions are drawing on only half of the talent pool and there is therefore a potential loss of intellectual capital. There is also a potential loss of investment. If women are being trained as psychiatrists and junior researchers, it would make sense to ensure a return on such investment. Women may also bring a varied perspective on mental health issues.

Why then are women less likely than men to advance to the senior ranks of academia? The research career is based around publishing in refereed journals and raising one's profile at key conferences, both of which can be heavily compromised by maternity leave or a partner relocating to a new institution or country. Carr et al (1998) reported that women with children had significantly fewer publications and slower self-perceived career progression compared with men with children, whereas there were no significant differences between the sexes for medical academics without children. The short-term contracts also make it difficult for women to sustain a career and manage a family. Mobility is an important element of research training through experience in different units and, although this can be exciting, it can be difficult for women with other responsibilities. Although there is now a greater use of information technology to keep in touch, global travel is still seen as important.

The recent Greenfield Report (Greenfield et al, 2002) acknowledges the under-representation of women in the higher echelons of the scientific research community and suggests that causes of this problem include few visible role models and mentors, the short-term contracts used for relatively senior academic positions, lack of transparency for pay and promotion procedures, gender imbalance in the decision-making processes of promotion and organisational policies, slow setting up and take-up of work life-balance policies and, particularly challengingly, the intangible cultural factors that seem to exclude women from the corridors of power. American studies also suggest that sexual harassment and gender discrimination are still common in academic medicine (Carr et al, 2000).

Women's perceptions might also contribute to the problem. The lack of female role models in senior positions might leave women feeling that there is no place for them in academic psychiatry. In addition, women might suspect that maternity leave and/or parttime working would not be looked on favourably by academic institutions. In fact, the main providers of research grants in the UK, for example the Wellcome Trust and the Medical Research Council, are now very flexible about part-time working and maternity leave in an attempt to redress the gender imbalance in academic life. However, there are few part-time jobs in academia and the concept of a senior part-time academic job holds little credibility, despite the fact that all clinical academics are to some extent part-time as they leave their academic 
an

editorial commitments for clinical services for a significant proportion of their working week.

It is possible for organisations to ensure that the most deserving junior academics are retained and promoted, irrespective of gender. At John Hopkins University School of Medicine a multi-faceted intervention in the early 1990s, which included problem identification, education, mentoring and reductions in structural career impediments, led to a $550 \%$ increase in the number of women at the associate professor rank over 5 years and improvement in timeliness of promotions, isolation and salary equity as reported by men and women (Fried et al, 1996). The Greenfield Report (Greenfield et al, 2002) recommends that the scientific community needs to be aware of institutional discrimination, there needs to be transparency in recruitment and promotion processes, awareness raising and equality training, implementation of work-life balance measures, and good employment practices that should include programmes targeted at women returners to accommodate their re-entry to academic careers after a period at home with child care responsibilities. Scientific research must also consider the gender dimension; this is very relevant to psychiatry, where gender has a major impact on the presentation and nature of psychiatric disorders and care and treatment needs.

The psychiatric profession clearly needs to recruit promising researchers and teachers. Sex disaggregated statistics need to be available to monitor psychiatric careers in the UK, and employing institutions should ensure that they adhere to the Greenfield recommendations. At a personal level, clinicians should encourage bright, interested male and female junior staff to pursue an academic career as it is an enjoyable and exciting area in which to work. Women also need to change their perceptions of the academic world - it is open to women, and wants to train and retain researchers who can produce high quality psychiatric research and contribute to improvements for our patients.

\section{References}

CARR, P. L., ASH, A. S., FRIEDMAN, R. H., et al (1998) Relation of family responsibilities and gender to the productivity and career satisfaction of medical faculty. Annals of Internal Medicine, 129, 532-538.

_ - _ et al (2000) Faculty perceptions of gender discrimination and sexual harassment in academic medicine. Annals of Internal Medicine, 132, 889-896.

FRIED, P. L., FRANCOMANO, C. A., MACDONALD, S. M., et al (1996) Career development for women in academic medicine: multiple interventions in a department of medicine. Journal of the GREENFIELD, S., PETERS, J., LANE, M., et al (2002) The Greenfield report on Women in Science, Engineering and Technology. London: Department of Trade and Industry.

KILLASPY, H., JOHNSON, S., LIVINGSTON, G., et al (2003) Women in academic psychiatry in the United Kingdom. Psychiatric Bulletin, 27, 323-326.

NONNEMAKER, L. (2000) Women physicians in academic medicine new insights from cohort studies. New England Journal of Medicine, $\mathbf{3 4 2}$ 399-405.

American Medical Association, 276 $1954-1955$.

Louise Howard Health Services Research Department, Institute of Psychiatry, De Crespigny Park, London SE5 8AF 